\title{
Surgery for Central, Parietal and Occipital Epilepsy
}

\author{
Theodore Rasmussen
}

\begin{abstract}
Patients with epileptogenic lesions that are more or less restricted to the central, parietal or occipital regions represent $14 \%$ of our total epilepsy surgery series and consisted of 322 patients at the end of 1980 . Tumoral or major vascular lesions were present in 117 patients (37\%), but this report is limited to the remaining 203 patients (63\%) with non-tumoral epileptogenic lesions. The presumed etiology was birth trauma or anoxia in $25 \%$, postnatal brain trauma in $25 \%$, and unknown in $24 \%$, miscellaneous lesions were present in $16 \%$, post-inflammatory gliosis or multiple factors were present in the remaining $10 \%$. Follow-up data of 2-51 years' duration (median 18 years) are available for 186 of these 203 patients. Sixty-three patients (34\%) remain seizure-free. Forty-two patients (23\%) have a marked reduction of seizures. The remaining 81 patients $(44 \%)$ have a lesser reduction. The variation in clinical seizure patterns is considerably greater than in temporal lobe epilepsy. Focal sensorimotor phenomena are common at the onset, whether the seizures begin in the central region or further posterior. The success following cortical resection is equally gratifying and the failures just as distressing as in surgery for epilepsy involving other brain regions.
\end{abstract}

RÉSUMÉ: La chirurgie dans l'épilepsie centrale, pariétale et occipitale. Les patients avec lésions épileptogènes confinées aux régions centrales, pariétales et occipitales, constituent $14 \%$ de notre série chirurgicale de patients épileptiques totalisant 322 patients, en date de la fín de 1980. Des lésions de nature tumorale ou vasculaire ont été retrouvées chez 117 patients (37\%). Ces demiers ont été exclus de cet article, qui porte sur les 203 patients restants (63\%) avec lésions épileptogènes non tumorales. L'étiologie présumée a été un traumatisme ou une anoxie péri-natale dans $25 \%$ des cas et un traumatisme post-natal dans un autre $25 \%$ des cas. Chez $24 \%$ des patients, aucun facteur étiologique n'a été démontré et chez $16 \%$, des causes diverses ont été retrouvées. Une gliose post-inflammatoire ou des facteurs multiples étaient présents dans le dernier $10 \%$ des cas. Un suivi a été possible chez 186 des 203 patients, sur une période variant de 2-51 ans (médiane 18 ans). Chez 63 patients (34\%), les crises ont cessé totalement, sans récidive. Chez 42 patients (23\%), on a noté une réduction marquée des crises. Les 81 patients $(44 \%)$ restants ont noté une réduction modérée ou légère des crises. La variation dans le pattern clinique des crises est plus grande que dans l'épilepsie temporale. Les phénomènes sensori-moteurs sont fréquents au début des crises, que celles-ci proviennent de la région centrale ou d'une région plus postérieure. Les succès associés à une exérèse corticale sont tout aussi gratifiants, et les échecs tout aussi désespérants que dans la chirurgie pour l'épilepsie impliquant d'autres régions du cerveau.

Can. J. Neurol. Sci. 1991; 18:611-616

Epileptogenic lesions that are more or less restricted to the central, parietal or occipital brain regions are the three smallest anatomical subdivisions of the Montreal Neurological Institute (MNI) surgical seizure series (Figure 1). Together they represent $14 \%$ of the total series and consisted of 322 patients as of the end of 1980 . The percentage of tumoral lesions in these 3 anatomical subgroups, $37 \%$ (Figure 2), is higher than in the temporal or frontal anatomical subdivisions ${ }^{1-4}$ primarily due to our tendency to operate with the special surgical seizure techniques in patients with recognized tumors that are in or near the motor or speech zones, even when seizures are of secondary importance, in order to facilitate the maximum safe removal of the tumor. On the other hand, a patient with a similar tumor in the temporal or frontal lobe would usually be operated upon with standard brain tumor techniques and thus would not appear in the surgical seizure series, unless the seizures were the patient's primary neurological symptom.
This report will be limited to the 203 patients with nontumoral epileptogenic lesions of this supratentorial area of the brain. The potential etiological factors are more evenly divided in this group than is the case in the frontal, temporal and multilobe subgroups. ${ }^{4}$

As in the case of frontal lobe epilepsy, the effectiveness of the various types of cortical excisions in reducing the seizure tendency has been significantly less than in the temporal lobe series, with $56 \%$ of patients achieving a complete or marked reduction of seizure tendency (Figure 3 ).

This is a particularly interesting group of patients with several aspects that have not been widely discussed. The following four brief, capsule case reports will illustrate 3 of these features.

The first aspect concerns the great variation in extent of the cortical excisions in the central region that suffice or are required to produce a satisfactory reduction of the seizure tendency. 
The first patient, J.Ho, has had the smallest successful cortical excision in the entire MNI surgical seizure series (Figure 4). This boy had 2 isolated convulsions in infancy, one with measles and one with pertussis. His recurring seizures started at 10 years of age. The minor attacks, averaging 2-10 per week, started with a feeling of awkwardness and insecurity of the left leg. This was quickly followed by weakness and then by inability to move the leg. On 1, 2 or 3 occasions per year the minor attacks progressed to severe 5-20 minute generalized convulsions.

Dr. Penfield operated upon him in 1941. Dr. Jasper, with his early 4 channel EEG unit for cortical recording, found epileptic

Montreal Neurological Institute Surgical Seizure Series Anatomical Classification - patients operated upon 1929 through 1980

\begin{tabular}{lrl}
\hline \hline Temporal lobe & 1210 pts. & $(56 \%)$ \\
Frontal lobe & 402 pts. & $(18 \%)$ \\
Central (sensorimotor) region & 151 pts. & $(7 \%)$ \\
Parietal lobe & 141 pts. & $(6 \%)$ \\
Occipital lobe & 30 pts. & $(1 \%)$ \\
Large multilobe lesions & 243 pts. & $(11 \%)$ \\
\hline & Total & 2177 pts. \\
\hline
\end{tabular}

Figure I-(from Rasmussen, reference 8)

Central, Parietal and Occipital Epileptogenic Lesions Etiology

$\left.\begin{array}{lrl}\hline \hline \text { Birth trauma or anoxia } & 51 \text { pts. } & (16 \%) \\ \text { Postnatal trauma } & 49 \text { pts. } & (15 \%) \\ \text { Postinflammatory brain scarring } & 17 \text { pts. } & (5 \%) \\ \text { Multiple potential etiological factors } & 6 \text { pts. } & (2 \%) \\ \text { Miscellaneous } & 33 \text { pts. } & (10 \%) \\ \text { Unknown } & 47 \text { pts. } & (15 \%) \\ \text { Tumoral and vascular lesions } & 117 \text { pts. } & (37 \%)\end{array}\right]$

Figure 2 - (from Rasmussen, reference 8) spiking in the right parasaggital central area. Electrical stimulation here reproduced the boy's aura of leg sensation. A $1 \times 2$ centimeter segment of the leg area of the precentral gyrus was excised and the tissue found to be severely gliotic.

There was marked weakness of the leg postoperatively. This lessened progressively during the following weeks and months, ultimately leaving the patient only a moderate but permanent limp. He had 1 major attack in the 14th and 1 in the 16th postoperative year. Otherwise, he has been seizure free to his last report in 1983, 42 years postoperative.

The next patient, L.La., a research chemist with a major pharmaceutical company, also had somatosensori-motor seizures arising in the right hemisphere. He required a much more extensive cortical resection (Figure 5). At 35 years of age he began to have slight sensory seizures or auras involving the left hand. Several months later these spread on several occasions to involve chronic jerking of the left hand with progression over the left side of the body and then to a generalized clonic convulsion. He was investigated by the late Dr. Rudolph Yeager of Philadelphia and found to have a large, linear arteriovenous malformation (AVM) of the right central region.

At operation, the AVM was found to lie at the anterior margin of the precentral gyrus and extended from the fissure of Sylvius up to the saggital sinus. Dr. Yeager excised the AVM completely in January 1954. After the patient recovered from the operation the sensorimotor status of his left arm and leg was normal. The left arm seizures recurred, however, after a couple of months and increased in frequency to several per day.

In August 1954, 7 months after the AVM operation, Dr. Yeager reoperated and excised a cubic centimeter or two from the bed of the AVM removal, at a level he estimated to be the arm area. Following this second operation there was a slight weakness of the left hand grip and a moderate decrease in 2 point discrimination in the hand, both of which have persisted.

The seizures continued, however, increased progressively in frequency and began to be precipitated by thumb movement. The patient had to avoid any left thumb movement in order to carry on with his laboratory work. He made himself a plastic forearm and hand brace which immobilized the thumb and hand in extension, and with this brace in place he was able to continue

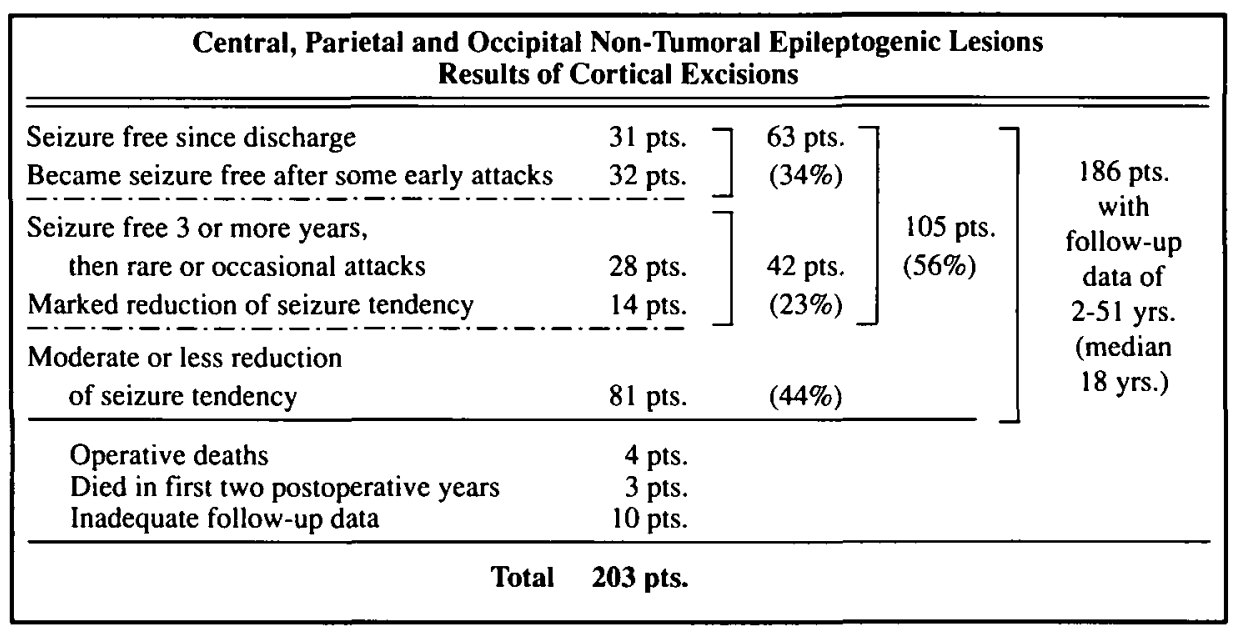

Figure 3 -(from Rasmussen, reference 8) 
his laboratory work, holding beakers and flasks with the other 4 fingers. If he was careful to avoid quick or strong movement of the fingers he could get through most days without too many seizures.

When he was referred to the MNI, 4 years after the onset of his trouble, his neurological examination was normal except for the slight weakness and moderate decrease in 2 point discrimination in the left hand noted above. Voluntary or passive movement of the left thumb produced a clonic left arm seizure 9 times out of 10. Voluntary finger or hand movements induced the attack about half of the time. Occasionally, a movement of the whole left arm would induce the typical clonic arm seizure.

An angiogram showed a normal appearance of the right middle cerebral artery and branches and no remnant of the AVM. The EEG showed small spikes at $\mathrm{C} 4$. In the small attacks, repetitive spike discharges remained well localized to the right central region. In larger attacks the spike discharges spread posteriorly and inferiorly and then to the opposite central and parietal region.

The patient was advised that a large removal of the sensorimotor arm area would probably be necessary to produce a worthwhile reduction of the seizure tendency. He was warned that this would produce a loss of individual finger movements, but that a useful grip would be preserved and, barring complications, there would be no weakness of the leg. He was sent home to discuss this with his family and with the referring neurologist.

He returned for operation 3 months later. The pre- and postcentral gyri were removed individually from the Sylvian fissure upward in several stages until stimulation of the cut surface of the 2 gyri produced trunk movement or sensation. There was by that time a flaccid paralysis of the whole left arm, but passive movement of the thumb continued to induce the clonic arm seizures. The convolutions behind and in front of the pre- and

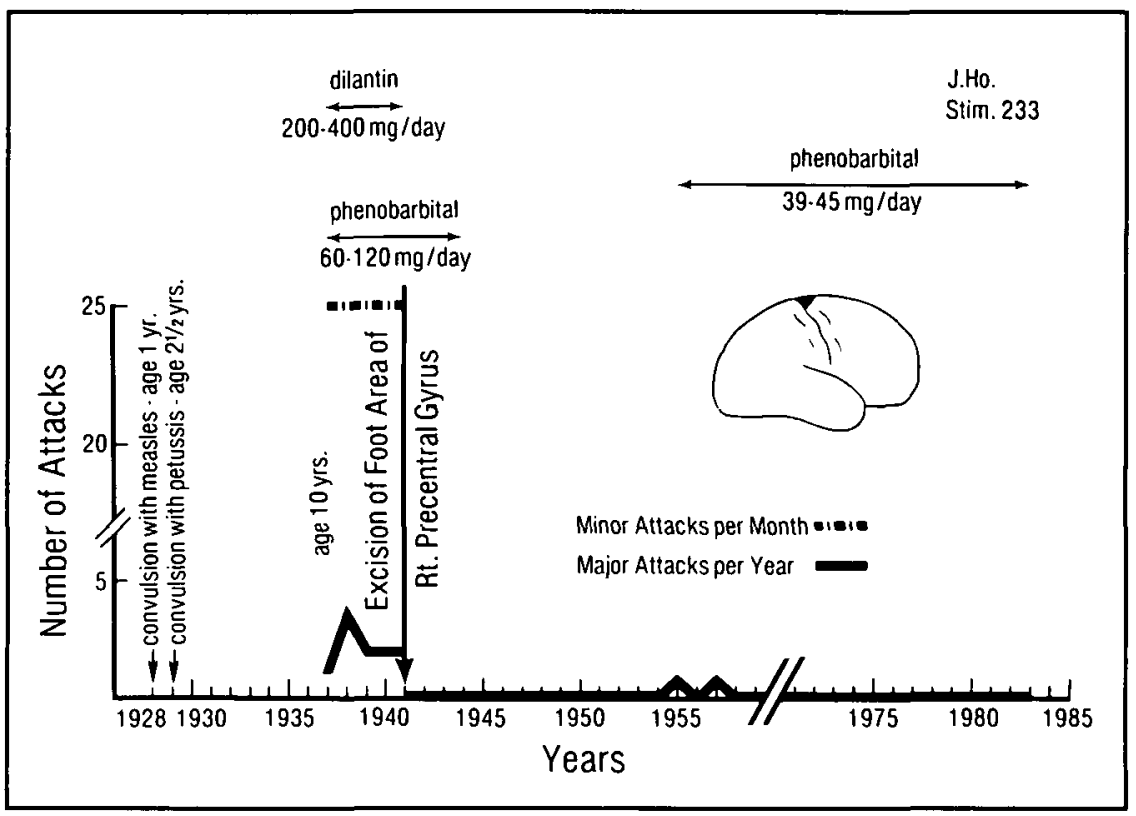

Figure 4-Seizure frequency analysis, patient J.Ho.

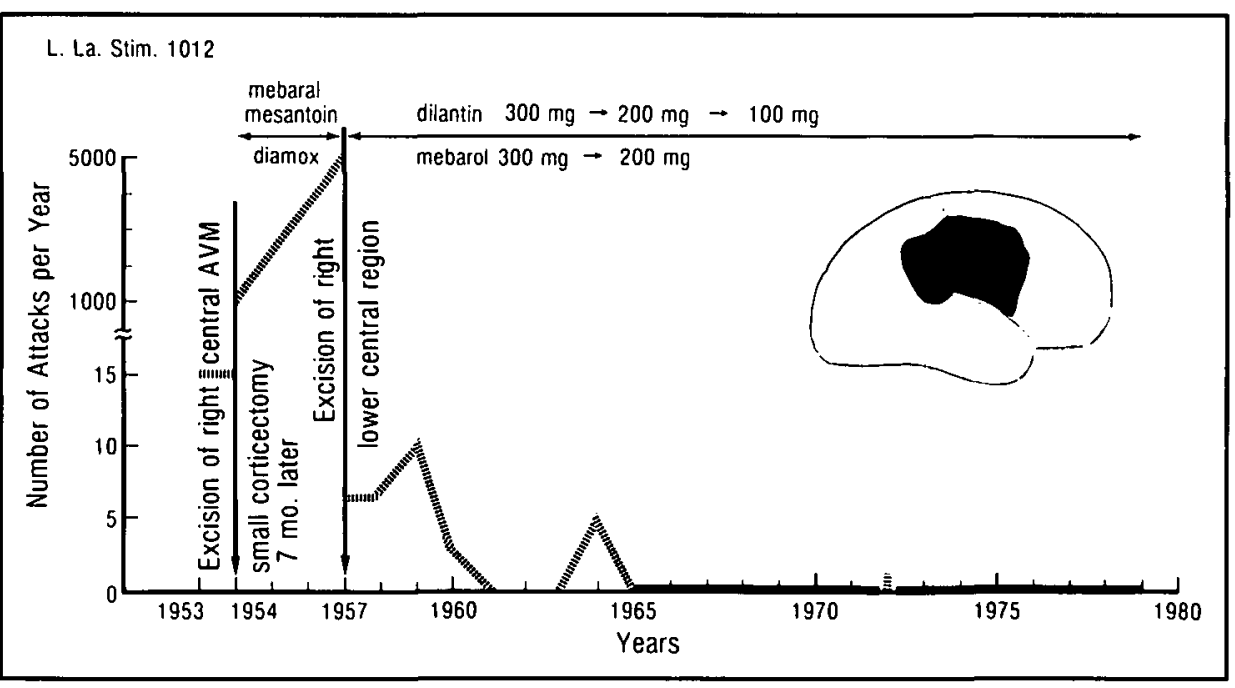

Figure 5-Seizure frequency analysis, patient L.La. 
post-central face and arm area were then removed one by one until passive thumb or hand movement and electrical stimulation failed to produce a seizure (Figure 5).

The next day there was a complete flaccid paralysis of the entire left arm and shoulder, but only a slight weakness of the leg. Power in the arm began to return 10 days later. One year postoperative the left hand grip was about $50 \%$ as strong as on the right, elbow and shoulder movement strength were about 60 $70 \%$. At a check-up 4 years postoperative, the strength of the grip was unchanged at about 50\% but he felt the hand grip was more useful. Pronation and supination remained at about $50 \%$ but power of elbow flexion and extension had improved to about $80 \%$. Left shoulder movements were nearly as strong as on the right. He was playing golf in the upper 90's but was distressed that he could no longer beat his teenage son.

He had 7 minor motor attacks involving his left shoulder in the 1 st postoperative year, 10 in the second, 2 in the $3 \mathrm{rd}$ and 4 or 5 in the 7th. He has been seizure free since then to his last report in 1979, 22 years postoperative (Figure 5).

The marked motor precipitation of L.La's seizures is of special interest and has been noted in several other patients with central epileptogenic lesions but is not present in the great majority of the patients in this group and is rarely seen in the other anatomical subgroups of the MNI surgical seizure series.

The next patient G.Ge, with similar sensori-motor attacks, required only a medium sized cortical excision limited to the central gyri to achieve a satisfactory reduction of the seizure tendency. His seizures arose in the central region of his left, dominant, hemisphere (Figure 6). There was clear post-ictal dysphasia after some of his bigger or more frequent attacks. A removal limited to the motor face area and the face and lower part of the sensory arm area, satisfactorily reduced his seizure tendency. There was marked dysphasia in the early postoperative period. This cleared up progressively and several late follow-up examinations have shown normal speech function.

He had 2 minor attacks in the first postoperative year and several brief sensory auras during the next 3 years. Since then he has been seizure free to his last report in 1986, 27 years postoperative and 3 years since Figure 6 was made.

His case provides another example of the variation in extent of the cortical excisions carried out in this brain region. One can only speculate on the factors that might play a role in the disparity in extent of the cortical excision that was required in these 3 patients with rather similar types of seizures.

Patient G.Ge also provides a good illustration of the fact that coordination of the speech functions of the anterior and posterior cortical speech areas is not mediated by cortical-cortical connections through the pre- and post-central gyri. 5,6

The final case report (patient E.Br.) illustrates the third interesting feature that has been encountered in some of the patients in this anatomical subgroup, namely the presence of organized bilaterally synchronous epileptiform lesion discharges in the EEG secondary to a unilateral focal epileptogenic lesion. Since the landmark 1952 paper of Tükel and Jasper ${ }^{7}$ this has been recognized as a not uncommon feature in patients with frontal lobe and multilobe seizure problems. ${ }^{4,8}$ Its presence, but less frequently, in temporal lobe epilepsy has also been well documented. Patient E.Br. illustrates the fact that the parietal lobe is likewise not immune to this phenomena.

Patient E.Br. was born after a 4 day labor with her head badly marked by forceps but no clinical evidence of brain injury. She was dropped to the floor on the 3rd or 4th day of life and sustained an occipital scalp laceration, but again there was no evidence of brain injury. At 7 months of age she began having frequent salaam attacks which stopped 4 months later. Minor attacks recurred at 3 years of age. There were several changes in her seizure patterns during the next four years, but on admission at 10 years of age her seizures consisted of stiffening, then twitching of the left arm and leg. Occasionally the onset was associated with a sensation in the left eye or a vague formed or unformed visual hallucination.

She had a partial left homonymous hemianopsia but otherwise her neurological examination was normal. X-ray studies showed evidence of a large atrophic area involving the posterior portion of her right cerebral hemisphere. Her EEG was dominated

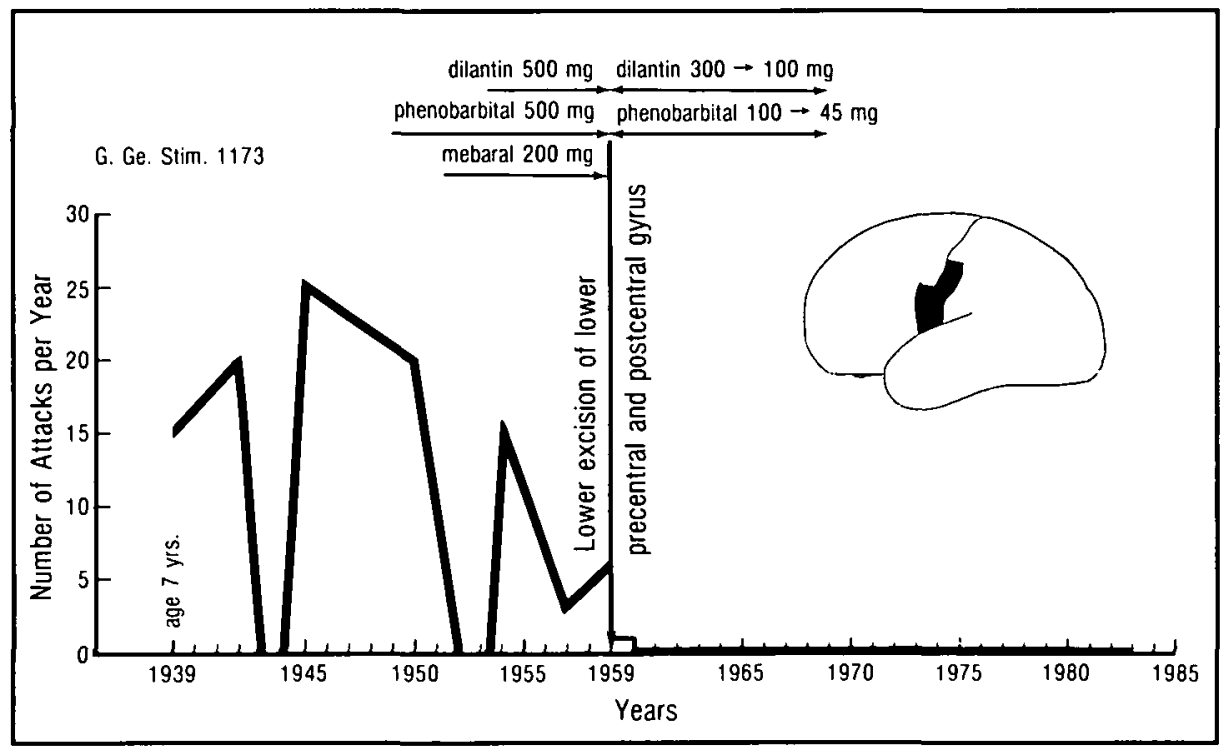

Figure 6-Seizure frequency analysis, patient G.Ge. 
by frequent bursts of $2^{1 / 2}$ to 3 per second bilaterally synchronous spike wave complexes (Figure 7).

Operation disclosed a whitish area of destroyed cortex replacing most of the convexity of the right occipital lobe. The cortical EEG showed widespread spikes and spike wave complexes over most of the parietal and temporal regions. A radical removal of the occipital, posterior parietal and temporal regions was necessary to eradicate the epileptiform activity in the cortical EEG.

She had 3 major seizures $1 \frac{1}{2}$ years postoperative. Since then she has been seizure free to her last report in 1974, 14 years postoperative when she became lost to follow-up (Figure 8).
In summary, this area of the brain generates seizure problems that present many of the same unexplained neurophysiological phenomena seen in association with epileptogenic lesions of other brain areas. The variation in clinical seizure patterns is considerably greater than in typical temporal lobe epilepsy. Focal sensorimotor phenomena are common at the onset, whether the seizures begin in the central region or further posteriorly. The successes following cortical resection are equally gratifying and the failures just as distressing as in surgery for epilepsy involving other brain regions.

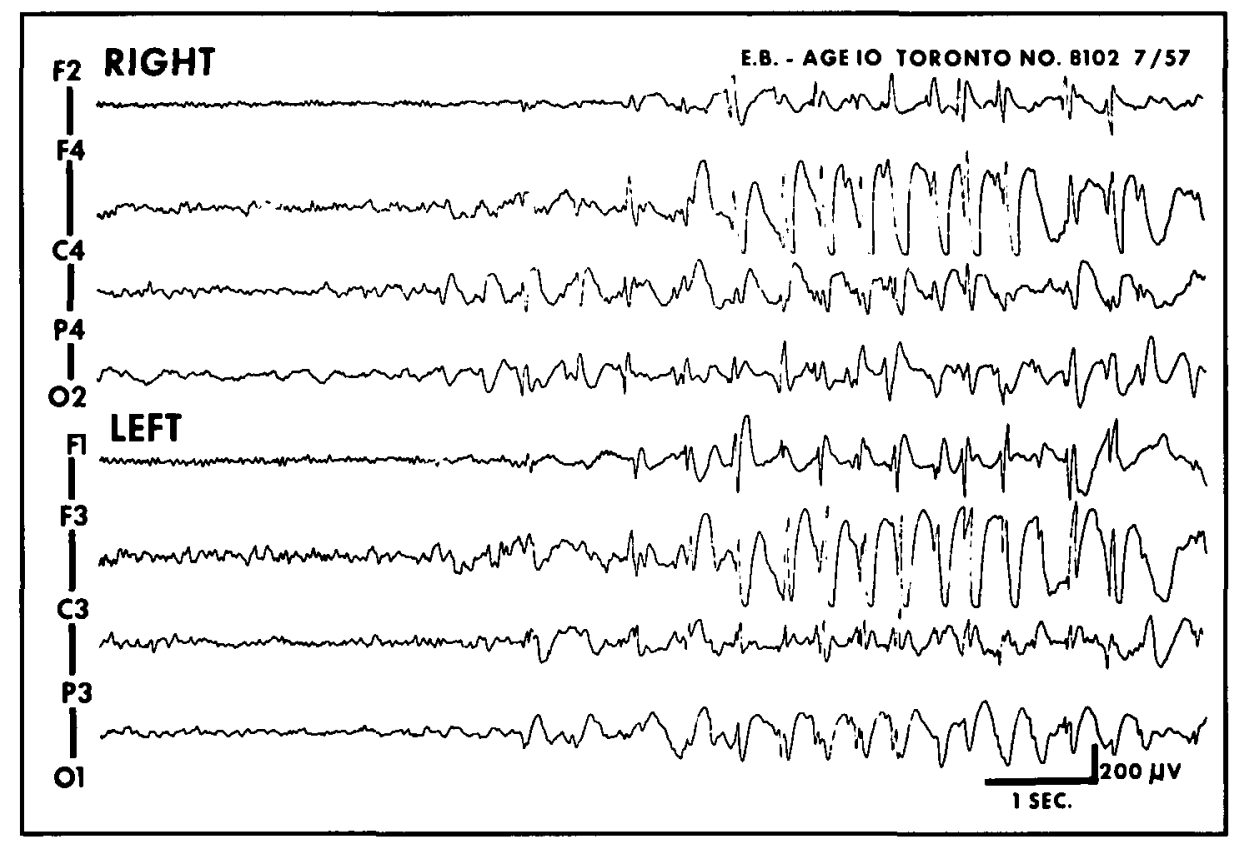

Figure 7-Preoperative EEG, patient E.Br.

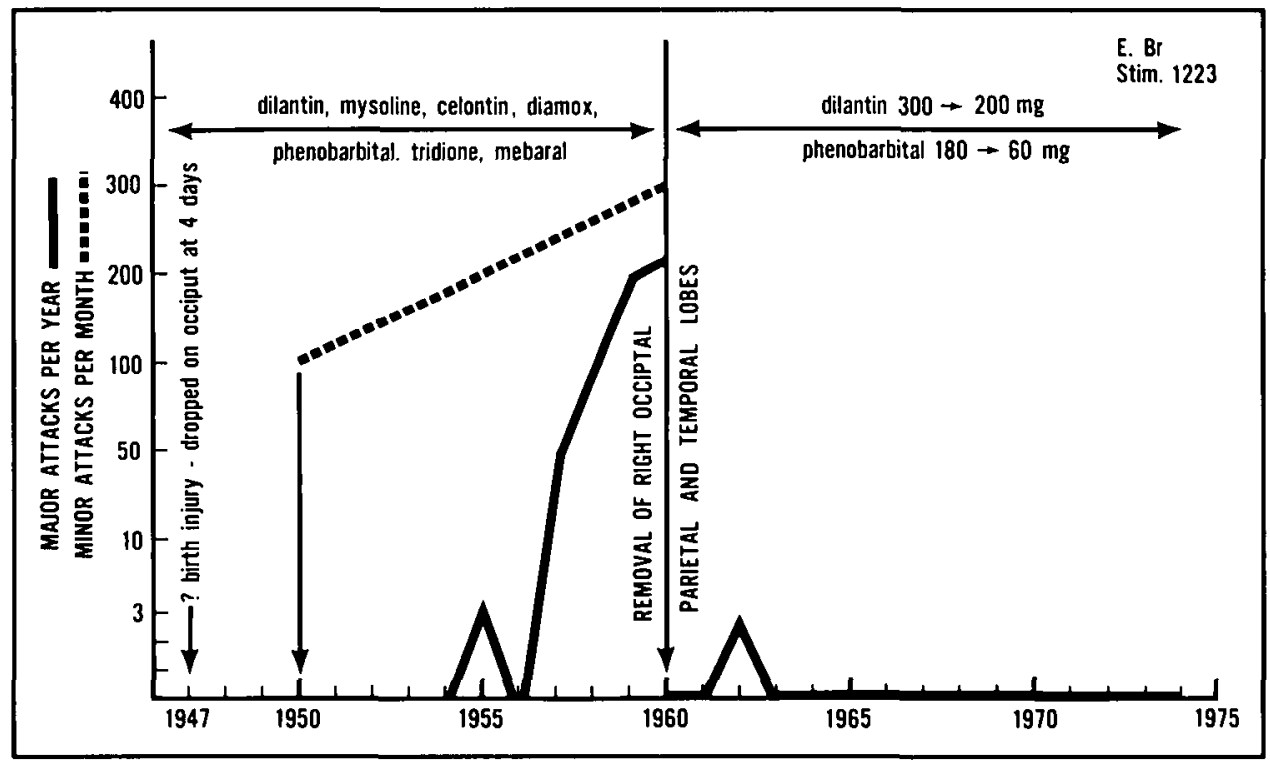

Figure 8-Seizure frequency analysis, patient E.Br. 


\section{REFERENCES}

1. Rasmussen T, Blundell J. Epilepsy and brain tumor. In: Fisher RG, ed. Clinical Neurosurgery. Baltimore: Williams \& Wilkins 1961; 138-156.

2. Leblanc F, Rasmussen T. Cerebral seizures and brain tumors. In: Vinken PJ, Bruyn GW, eds. Handbook of Clinical Neurology Vol. 15. Amsterdam: North Holland Publishing Co. 1974; 295301 .

3. Rasmussen T. Surgery for epilepsy associated with brain tumors. In: Purpura DP, Penry JK, Walter RD, eds. Neurosurgical Management of the Epilepsies, New York: Raven Press 1975; 227-239.

4. Rasmussen $\mathrm{T}$. Cortical resection for medically refractory epilepsy: results, lessons and questions. In: Rasmussen T, Marino R, eds. Functional Neurosurgery. New York: Raven Press 1979; 253 269.
5. Rasmussen T. Surgery for epilepsy arising in regions other than the temporal and frontal lobes. In: Purpura DP, Penry JK, Walter RD, eds. Neurosurgical Management of the Epilepsies. New York: Raven Press 1975; 207-226.

6. Rasmussen T, Milner B. Clinical and surgical studies of the cerebral speech areas in man. In: Zulch KJ, Creutzfeldt, Galbraith GC, eds. Cerebral Localization. Berlin Heidelberg. Springer-Verlag 1975; 235-257.

7. Tükel $\mathrm{K}$, Jasper $\mathrm{H}$. The electroencephalogram in parasaggital lesions. Electroencephal Clin Neurophysiol 1952; 4: 513-526.

8. Rasmussen T. Focal epilepsies of non-temporal and non-frontal origin. In: Weiser HG, Elger CE, eds. Presurgical Evaluation of Epilepsies. Berlin Heidelberg. Springer-Verlag 1987; 300-305.

9. Rasmussen T, Milner B. The role of early left-brain injury in determining lateralization of cerebral speech functions. Ann Acad Sci 1977; 299: 355-369. 